\title{
Influence of Provision of Physical Facilities on Participation in Early Childhood Development and Education in Public Primary Schools in Embu County, Kenya
}

\author{
Kamwitha Anastasia Muthanje, PhD \\ Dr. Ibrahim Khatete, Senior Lecturer \\ Dr. Andrew Riechi, Senior Lecturer
}

Department of Educational Administration and Planning

School of Education, University of Nairobi, Kenya

\begin{abstract}
Mainstreaming of Early Childhood Development and Education (ECDE) in primary schools has been a policy in the Kenyan educational system. The philosophy is to induct the learner at this level into primary school environment. However, this is not without challenges. The children at this level of ECDE have not developed enough to independently function. This has led to the need to examine how they are coping. It is with this background that the researcher examined the influence of the provision of physical facilities on participation in ECDE in public primary schools in Embu County, Kenya. A total of forty-two ECDE teachers took part in the study. The main tool for data collection was a questionnaire, observation schedule, and document analysis. Quantitative method was used to analyse data using Statistical Package for Social Sciences (SPSS). Findings from the study indicated that physical facilities influenced children's participation in ECD classes. This paper focuses on proposing the need for relevant stakeholders in education to invest in physical facilities so as to increase participation in early childhood development and education.
\end{abstract}

Keywords: Facilities, Participation, Childhood, Development

\section{Introduction}

Education is a productive investment in human capital that equips learners with knowledge, skills, and appropriate attitudes. This enables them to increase their productive capacities and receive higher salaries in future. It has also been known to contribute to economic development and social 
progress. Investment in education is not only a basic human right, but also a basic component of social and economic development (World Bank, 1990). It is important to note that investment in education has greater future economic dividends (Psacharopolous \& Woodhall, 1985). This implies that investment in early childhood learning improves learning skills which later affects prospective career skills (Young, 1996).

The philosophy of early childhood development is ideal to understanding its purpose. According to Folque (1998), the MEM (Movimento da EscolaModerna) otherwise known as Modern School Movement model proposes a curriculum based on real life. Essentially, the philosophy behind early childhood education is that 'curriculum is life'. The vital concern is to offer a learning that is totally assimilated into the cultural background of the society the child lives in rather than constructing some form of niche outside it (Folque, 1998). From a philosophical perspective, education begins with the cultural life experience of children which forms the basis for the acquisition of new skills. In reference to Niza (1995) and Folque (1998), they reiterate that teachers often assume that children know nothing at their entry into school. However, this is not true and early childhood education wants to avoid this. The sole purpose of early childhood education is to provide an opportunity for the teacher to utilize what the children know (real life experience outside school) and use it as a starting point to develop the children's skills (Niza, 1995).

Early years of human growth and individual enactment are important throughout life. The negative significance of low ECD levels undermines the expected social and economic benefits of public (governmental) and private (parental) investments in children's health and education at later stages in life. They are likely to affect the aggregate economy based on the quality of the human resources available in the labour market and their ability to effectively contribute to the country's economy (Robio-Codina Orazio, Costas Varela \& Graham-McGregor, 2013).

ECDE is a key component in the promotion of education in Kenya as it sets foundation for the children. Therefore, it addresses inadequacy of the influence of physical facilities on participation of children at next level. In this study, a close analysis on the influence of provision of facilities on participation of ECDE in Embu County, Kenya, is carried out. School facilities are a key base for learning in schools. School facilities include classrooms, resource centres and dormitories for boarding schools; open fields for games; games equipment; and sanitation facilities (MOE, 2001). Day to day learning takes places in the classroom. In the field, extracurricular activities take place. Children and teachers also need sanitation facilities such as toilets, waste disposal services, and clean water to enhance participation. 
The physical spaces need to be adequate with up to date infrastructures which meet standards set by the Ministry of Education (MOE, 2001). The doors and windows need to be open in order to allow free flow of air in and out of the classroom. In addition, windows should not have grills. This helps eradicate serious accidents that could otherwise result to low participation of the affected children in search of medical attention. When doors and windows without grills are fully opened, the children would be able to escape with ease in case of any fire breakout or any other eventuality (MOE, 2008).

In terms of health and sanitation, the school facilities should be provided in the ratios as recommended by MOE. The safety and standards manual in government institutions recommends one toilet for every 30 boys (1:30) and one toilet for every 25 girls (1:25). Running water and a number of water points per pupil are a key concern in maintaining basic hygiene standards. This ensures continuity of the learning process by the learners since the risk of sickness resulting from infection is reduced (MOE, 2008).

The average standard as recommended by the MOE (2006) is that an ECDE centre shall provide safe drinking water to be used in the kitchen, for play activities, drinking, and for washing hands. Most of the schools in the study area did not have adequate water facilities and this was a major reason for not washing hands (Embu County Government, 2016). This affected continuity of the learning process of the children in pre-school since such children have low attendance which eventually results to low participation. Thus, this leads to poor achievement of competencies. The World Health Organization, WHO (1997), argued that lack of adequate water and sanitation facilities in schools create unsafe environment where diseases are transmitted. When children contact diseases, they eventually remain at home for long so as to recover.

The review of literature has shown that physical facilities in schools play a critical role in teaching and learning process. Despite this role, it appears that no adequate studies have been conducted to link physical facilities and school participation in early childhood development and education in Kenya's context. Given this knowledge gap, this study intended to examine the influence of provision of physical facilities on children's participation in early childhood development and education in public primary schools in Embu County, Kenya.

\section{Research Objective}

The objective of this research was to establish the influence of provision of physical facilities on participation in early childhood development and education in public primary schools in Embu County, Kenya. 


\section{Literature Review}

\section{The Concept of Participation in Early Childhood Development and Education}

An education reform in the Republic of Mauritius (2009) established pre-primary school to be the most essential starting point for all future education. Children aged between 3-5 years have an opportunity to develop their individual intellectual, social-emotional, and psycho-motor skills to the best of their capacity in order to build the confidence and self-esteem they need in their education. This prepares them for primary school, lays the foundation for learning, and contributes to improved participation. Participation in early childhood development and education is a wide concept that encompasses student enrolment, academic performance, less absenteeism, and less repetition among other aspects. This in turn increases transition rates in primary schools and improvement on internal efficiency.

According to Psacharopolous and Woodhall (1985) in their book on education for development titled "An analysis of investment choices," internal efficiency is viewed to be concerned with the relationship between inputs and outputs within the education system or within individual institutions. Output in this case can be measured in relation to participation in early childhood development and education. It was noted in the Philippine Education for all (2015) that to increase internal efficiency which entails participation in schools, facilities such as classrooms, desks/armchairs, textbooks, teachers, and appropriate class size among many other things are necessary.

\section{Influence of Provision of Physical Infrastructure on Participation in Early Childhood Development and Education in Public Primary Schools}

Infrastructure is the physical component of interrelated systems that help to sustain ECDE. There were no adequate classrooms to accommodate pre-primary pupils in Argentina; thus, the government financed massive public school construction program. A similar situation of inadequacy of physical infrastructure in schools was experienced in Cuba. The government incrementally built a national system of day-care centres and early childhood and day-care programmes that reach 98.3 percent of children in the 0-6 age group. This has enhanced participation in early childhood development and education through improved academic performance in the country. This was confirmed in a 1998 comparative study of grades 3 and 4 in 11 Latin American countries. The results showed that Cuban children scored significantly higher (100 points ahead of the regional average in the third-grade mathematics). This eventually improved participation through reduced dropouts in subsequent grades in primary schools. Furthermore, participation was evident through the expansion of classrooms that was associated with a large increase in preprimary enrolment by 10 percent. 
Furthermore, the expansion of financing kindergarten reduced grade repetition which contributed to improved participation in the Southern and Western United States. It was also noted that when pre-schools are not located in public schools, pre-school education is associated with higher levels of behavioural problems which may eventually lead to pupils' dropout. This results to experiencing internal inefficiency (Berlinski, Galiani \& Gentler, 2006). This was found relevant by Chaudhury et al. (2005) who noted that schools in Bangladesh, Ecuador, India, Indonesia, Peru, and Uganda with better infrastructure had lower absenteeism rates. Thus, there were fewer dropouts of learners. This improved participation of learners in these schools.

In Latin America, double-shift schools were introduced in an attempt to use existing buildings and equipment more intensively. This improved participation of learners in early childhood development and education. It was found that the extent to which intensive use of physical facilities increase participation depends not only on the method of organization ${ }_{2}$ but also on the availability of teachers and the spare capacity. A number of World Bank projects have attempted to improve the utilization of existing facilities through the increased use of double shifts systems (as in Colombia, El Salvador, and Indonesia) and rotating the use of classrooms (as in Cameroon, Guyana, and Sierra Leone) (Psacharopoulos \& Woodhall, 1985). Psacharopoulos and Woodhall (1985) further confirmed that in Colombia, El Salvador, and Indonesia there was a problem of educational facilities. The World Bank projects attempted to improve the utilization of existing facilities through the increased use of double shift system. To solve the same problem in Cameroon, Guyana, and Sierra Leone, rotational use of classroom was introduced. Its findings showed that intensive use of physical facilities increased population of pupils in schools. However, this depended on organization, availability of teachers, and spare capacity.

A study done in Uganda showed that the physical infrastructure of primary schools was inadequate. Infrastructure such as classrooms and toilets were in poor conditions. This posed health and security risks to learners and consequently affected learning. Further, inadequate toilet facilities were viewed to contribute to low participation of girls when they reach puberty. In effect, poor participation in early childhood development and education was found relevant by Watkins who noted that retention and learning are hampered when pupils attend school in dilapidated or overcrowded buildings and in classrooms that are poorly lit and ventilated (UNESCO, 2008).

In a 2004 survey conducted in Uganda, 32 percent of respondents reported that inadequate buildings in schools have been the most serious constraint to ECDE learner's performance. In an attempt to increase participation in early childhood development and education, the Ugandan government has been providing grant to school facilities. This has served to 
decentralize construction activities to district level. This exercise has led to the increased enrolment of learners in primary schools. This finding was found relevant by Lusk and Hashiemi (2004) who noted that infrastructure is the most serious obstacle among others to the creation of effective baby classes. They noted that there has been a lot of overcrowding in pre-schools as well as in Grade 1. Similarly, in Tanzania, education was faced with problems of dilapidated physical infrastructure. This decreased enrolment rates which contributed to high dropout rates, lack of teaching and instructional materials, as well as low morale among the teaching staff. Also, the government increased participation of local communities in school infrastructure construction and payment of teachers. This helped to supplement what the government gave for the running of schools.

Fabian and Dunlop (2007) noted that poor primary school infrastructure is a barrier to improving access to primary education in Kenya. On the other hand, improved primary school infrastructure is a high priority among schools. There is a backlog of infrastructure provision and shortage of permanent classrooms, particularly in poor districts. The existing infrastructure also was found to be in a poor condition due to lack of investment capital, poor construction standards, and inadequate maintenance. This scenario was especially observed to a great extent during the implementation of Free Primary Education (FPE). The poor situation of the physical infrastructure led to overcrowding which was not conducive to good learning environment. With time participation was affected since there were high dropout rates and low enrolments, particularly in poor and marginalized areas. This was found relevant by Owiti and Associates (2004) who observed that congestion and lack of sitting, learning/teaching, and play facilities discouraged some pupils who view ECD centres superior to lower primary school. Conversely, this negatively affected transition rates since they had to drop out of school.

Kangethe, Wakahiu and Karanja (2015) in their survey on "Assessment of the Early Childhood Development Policy Implementation in Kenya" observed that many public ECD centres used desks designed for bigger children. They lacked ramps for children with disabilities, as well as rails, lower door handles or any environmental adaptation for special needs children. They further noted that the ECD centres lacked physical facilities such as classes, desks, and chairs. There was also inadequate availability of land to start or expand ECD, though this was common in urban areas. This was found relevant by Republic of Kenya (2014) in a baseline survey carried out by the County Government of Embu between the periods of September October 2013. The report revealed that Early Childhood Care Education (ECCE) Centres had poor infrastructure for tuition and sanitation. The Centres also lacked playing facilities and adequate sleeping facilities, and they were 
located far from primary schools. The situation in Embu County is also similar to the findings of Kang'ethe et al. (2015) and the World Bank (2006) of many ECCE centres lacking play facilities, adequate sleeping facilities, and dilapidated physical facilities. Generally, the surveys recommended measures to be taken to increase access, retention, transition, and completion rates so as to curb decrease in pupils' enrolment and high dropout rates which in turn improve participation (County Government of Embu Report, 2013).

An article by Reject Online (2016) showed that many public primary schools have dilapidated and untidy pit latrines in Embu County public primary schools. These latrines are inaccessible because they are wet with urine. Further, many primary schools were characterised by lack of water, poor infrastructure, lack of leaky tins which are basic sanitary hand washing equipment, and broken water tanks which were empty. Teachers are further demoralized by working in dilapidated buildings with leaking roofs which are in need of repair. This discourages learners who end up dropping out of school since the teacher cannot motivate them. This was also reflected in the survey carried out in Embu County in the year 2013-2014.

As a step towards improving participation in early childhood development and education, Aila (2005) advised the government to increase learning facilities of ECD children since most ECDE programmes have inadequate physical facilities. This is not in conformity with the Basic Education Act (2013) article 64 which advocates every institution of basic education and training to have the outdoor playing facilities and equipment. This includes both outdoors and indoors with provisions for persons with disabilities, administrative offices, sanitary facilities including bathrooms for both learners and other persons segregated by gender and age, kitchen and dining room, standard classrooms measuring $7 \mathrm{~m} \mathrm{x} 6 \mathrm{~m}$ for 25 learners for preprimary learners, and a science room or other rooms for specialized subjects. MOE (2008) enumerates the safety standard guidelines which when properly observed can increase enrolment, retention, and completion. Consequently, this improves attainment and education quality. Some of the guidelines include: safety on school grounds, safety in physical infrastructure, health and hygiene safety, food safety, safety of children with special needs/disabilities, safety against child abuse, transportation safety, and school community relations.

\section{Research Methodology \\ Research Design of the Study}

The study adopted cross-sectional survey research design to assess the influence of provision of physical facilities on children participation in early childhood development and education in Embu County, Kenya. This research employed this design which enabled the provision of insight into intensive, 
descriptive, and holistic analysis of the collected data. The design was used since it quantified information that was utilized for descriptive analysis.

\section{Target Population and Study Area}

The study targeted head teachers, lower primary teachers, and ECD teachers in public primary schools in Embu County. Simple random sampling procedure was used to choose schools from each sub County for the study. Therefore, 10 percent of 96 schools in Mbeere North, 35 schools in Embu West, 68 schools in Embu East, 143 schools in Mbeere South, and 36 schools in Embu North were selected which translated to 10, 4, 7, 14, and 4 primary and ECDE Schools respectively for the study.

\section{Sampling Design and Sample Size}

Stratified random sampling procedure was used to arrive at the number and sample of primary schools, pre- primary schools, and teachers from each sub County for the study. The sample of $10 \%$ of 381 head teachers, $10 \%$ of 483 ECD teachers, and two primary teachers from each sampled primary school were used for the study. Thus, those who participated in the study were a total of thirty eight (38) head teachers, seventy six (76) lower primary teachers, and thirty eight (38) ECD teachers.

\section{Data Collection Instruments}

In regard to research instruments, questionnaire was administered to the selected sample of head teachers, lower primary teachers, and pre-school teachers. Observation schedule and document analysis was further used by the researcher to extract more information for the purpose of triangulation of the findings of the study. To bring order, structure, and interpretation to the mass of collected data, quantitative and qualitative information was analysed with the help of a statistical application namely Statistical Package for Social Sciences (SPSS) version 19 so as to inform the accuracy of the results (Sarantakos, 2013).

\section{Analysis and Findings \\ Demographic Characteristics of the Respondents}

Data on age, gender, academic qualification, and teaching experience of the teachers was sought.

The gender of head teachers was sought with the aim of establishing the distribution of head teachers by gender across all the schools. Nearly two thirds $(62 \%)$ of the ECD teachers were males while the rest $(38 \%)$ were females. This showed that many primary schools where ECD schools are part and parcel are dominated by male teachers. This meant that more male teachers have become interested in teaching pre-schools which has not been 
the case some years back. This is a great improvement on gender sensitivity in deployment of teachers which may improve attendance of children. ECD teachers with college and university level of education constituted $57 \%$ while those with certificates were $43 \%$. This showed that many teachers have upgraded their education and this is likely to improve performance in preschools and eventually lead to commendable transition to the next grade. The longest serving ECD teachers had 31 years of service. This showed stability in teaching career as a nursery school teacher which may improve performance and transition to the next grade. Those with the least year of service had 1 year of service. However, the average years of service for ECD teachers were 12 years. This implies that most of the ECD teachers had long experience in school management.

\section{Influence of Physical Facilities on Participation}

The study sought to examine the influence of provision of physical facilities on participation in early childhood development and education in primary schools within Embu County. The participants were asked to indicate whether the facilities were adequate and how this influenced participation in early childhood development and education.

\section{Adequacy of Physical Facilities}

The teachers were asked to indicate whether they agree or disagree with the statements related to adequacy of physical facilities. Figure 1 shows the distribution of teachers indicating adequacy of physical facilities in ECDE centers.

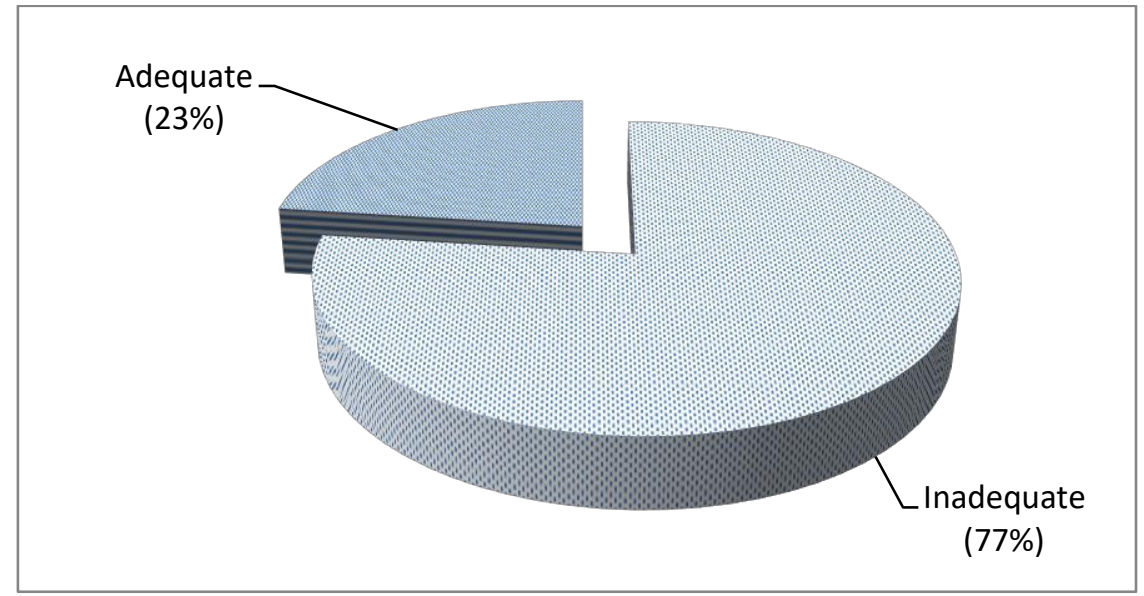

Figure 1. Adequacy of physical facilities in ECDE centers

As shown in Figure 1,77\% of the teachers indicated that the facilities were inadequate. They explained that these facilities such as classrooms had poor lighting, floors were rough, desks were not fit for big children, and most 
of them were not in good conditions. More so, children strained to use them. Windows had no panes and this resulted in a lot of cold circulation especially in the morning. These children eventually become victims of low participation which leads to children being out of school. This finding concurs with UNESCO (2008) report which observed that inadequate poor class lighting, poor condition of classes, and poor condition of desks for children contributed to low participation of children in Uganda and especially for the girl child. Some other facilities which were inadequate included classrooms, water taps, and playground. Hence, this negatively affected operations of the school.

\section{Extent to which Physical Facility Influenced Participation in ECDE Classes}

The respondents were asked to indicate the extent to which physical facilities influenced participation of children in ECD classes. The distribution of the responses is presented in Figure 2.

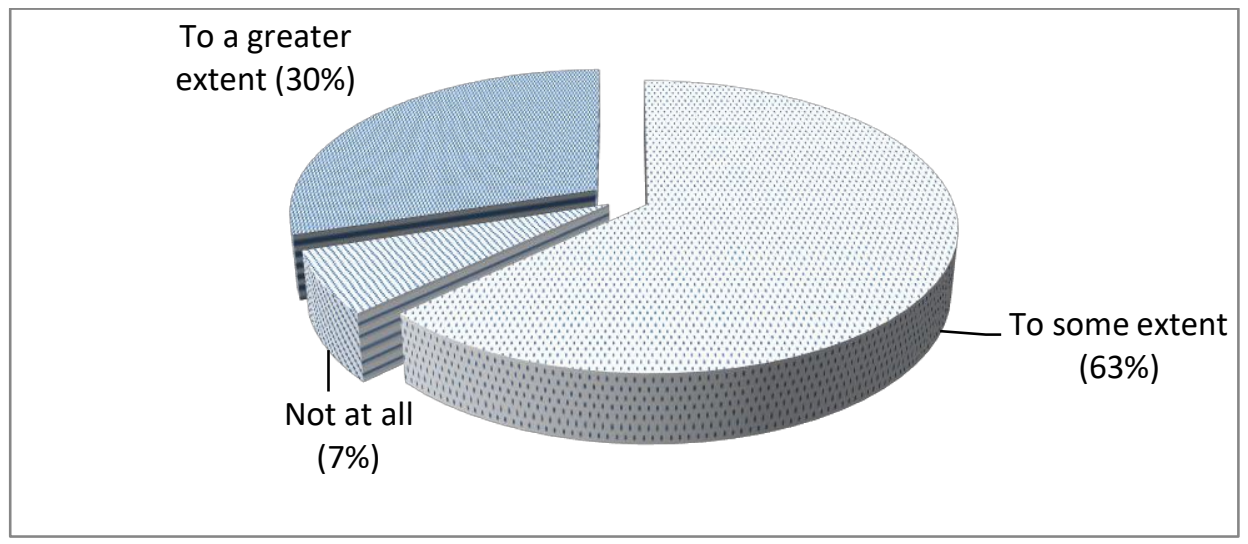

Figure 2. Influence of physical facilities on absenteeism in ECDE classes

Figure 2 shows that nearly two thirds (63\%) of the respondents indicated that to some extent facilities have influence on participation in ECD classes. This was attested by Fabian and Danlop (2007) who observed that inadequacy and poor condition of infrastructure was a contributory factor to low participation of children in primary schools in Kenya. Another $30 \%$ felt that it affected participation to a greater extent. Only $7 \%$ reported that it did not have any influence at all.

\section{Discussions and Conclusion}

This study has established that physical facilities such as toilets, water, and electricity are inadequate in primary schools. Therefore, this contributes to low participation in ECDE centers. This echoes the study by Lusk and Hashiemi (2004) who observed that poor infrastructure poses health and 
security risks. Thus, learning is adversely affected. Lusk and Hashiemi (2004) specifically highlighted toilets as facilities that have proved to contribute to low participation of girls in schools especially during puberty age. This is due to menstruation while at school and with no protective materials. Similarly, they noted that infrastructure is the most serious obstacle to the creation of effective baby classes. The explanation for their observation was overcrowding in pre-schools. The design of infrastructure affects learning especially when there is inadequate light, no proper air circulation, and poor quality furniture which is not made to fit the size of children. Also, simulation is not adequate especially when there is complexity and color of the wall and other materials which are not attractive to the children. Individualization becomes an impediment to children participation especially when the classes are congested. This poses no flexibility of the learning space. The results of this study also echoes the work of Britto (2012) who observed that physical condition of the space is important since it affects the health and safety of both children and adults.

The results also correspond with the work of Kang'ethe, Wakahiu and Karanja (2015) who stated that many public ECDE centers used desks designed for bigger children. They lacked ramps for children with disabilities, as well as rails, lower door handles or any environmental adaptation for special needs children. Moreover, they also indicated that the ECDE centers lacked physical facilities such as classes, desks, and chairs. There was also inadequate availability of land to start or expand ECDE in both rural and urban areas. This was found relevant by Republic of Kenya (2014) in a baseline survey carried out by the County Government of Embu between the periods of September 2013 - October 2014. The report revealed that ECDE Centers had poor infrastructure for tuition and sanitation. Besides being located far from primary schools, the Centers also lacked adequate playing and sleeping facilities. The situation in Embu County echoes the findings of Kang'ethe et al. (2015) and the World Bank (2006) which showed that many ECDE centers lacked playing and sleeping facilities. Additionally, the findings claimed that many centers had dilapidated physical facilities. In general, both surveys recommended measures to be taken to increase access, retention, transition, and completion rates so as to curb decrease in pupils' enrolment and low participation (Embu Development Plan, 2016).

\section{Conclusion of the Study}

From the findings in this study, it is evident that lack of adequate physical facilities affects the continuity of learning process of learners in ECDE centres. This is because of illness due to poor sanitation and inadequate classrooms that result in poor performance and low competency level. Eventually, learners opt to stay away from school when they feel inadequate. 
Lack of feeding program for the learners also affects performance since hunger affects learners' concentration in class. They end up staying at home if it is not taken care of. From this study, there is need for the relevant stakeholders in education to invest in physical facilities in order to lessen low participation in early childhood and primary education.

\section{Theoretical Implication of the Study}

The study aims to show how the Education Production Function Theory utilizes existing inputs to produce maximum output. Specifically, education is a kind of industry where people enter as raw materials and come out as finished products. The function shows relationship between two or more variables. These variables can be physical infrastructure, level of teacher professional qualification, level of pupil/teacher ratio, and provision of instructional materials. These are some of the factors contributing to poor participation in early childhood development and education, and this has led to low internal efficiency in ECD and primary schools.

\section{Limitations and Suggestions for Further Study}

This study had some limitations. Firstly, some of the information sought was confidential which could not be divulged by the respondents although they had to be assured of confidentiality. The other limitation was the busy schedules of the teachers, and it was necessary to book appointments with the school head prior to data collection day. There might have been more educational issues that may have been addressed during data collection. Future studies can provide more information from an exploration of a wider range of respondents from different educational institutions and sectors.

\section{References:}

1. Aila, P. (2005). Factors affecting the use of Aids in Pre-school in Asego Dingo Homa Bay District, Kenya. (Un Published MED Thesis) Kenyatta University, Kenya

2. Ahmad, E., Ayres, L., Fields, G., Ribe, H., Squire, L., Suridberg, M., Van de Walle, D., Vander, G. J., \& Walton, M. (1990). World development Report from http://documents.worldbank.org/curated/en/docsearch/author/m91475

3. Berlinski, Giliani \& Gentler (2006). Giving children a better start; Preschool attendance and school-age profiles. Journal of Public Economics 92 (2008) 1416-1440

4. Bertlett, K., Arnold, C., Gowani, S., \& Merali, R. (2004). Everyone Counts: Dalit Children and the Right to Education in Nepal. Nepal saves the Children US. Retrieved from 
https://www.researchgate.net/publication/274071458_Everyone_coun ts_Dalit_children_and_the_right_to_education_in_Nepal

5. Chaudhury, N., Hammer, J., Kremer, M., \& Mwalidharan, K. (2006). Missing in Action; Teacher and Health Worker Absence in Developing Countries Journal of Economic Perspectives-Volume 20, Number1Winter 2006-Pages 91-116

6. EFA Global Monitoring Report (2008). Chapter 2 the Six Goals: How far have we come?Paris: UNESCO.

7. Embu Development Plan (2016). Annual Development Plan: Towards Globally Competitive and Prosperous Kenya. Embu County Government

8. Fabian, H. \& Dunlop, A. W. (2007). Outcomes of good practice in transition Processes for children entering primary school, Working Paper 42. Bernard Van Leer Foundation: The Hague, the Netherland.

9. Folque, M. A. (1998). The Influence of Vygotsky in Movimento Da EscolaModerna Early Childhood Education Curriculum in Portugal Retrieved from https://dspace.uevora.pt/rdpc/bitstream/10174/3882/1/VygotskyMEM Ingle \%CC\%82s.pdf

10. Kangethe, S. N., Wakahiu, J., \& Karanja, M. (2015). Assessment of the Early Childhood Development Policy Implementation in Kenya: Journal of Education and Social Policy. Vol2, No 1.

11. Lusk, M. D. \& Hashiemi, M. N. (2004). Early Childhood Education: Context and Resources in Bangladesh. USAID

12. Mertens, D. M. (2010). Research and Evaluation in Education and Psychology: Integrating Diversity with Quantitative, Qualitative, and Mixed Methods $\left(3^{\text {rd }}\right.$ Ed.). Thousand Oaks: Sage Publisher.

13. Ministry of Education [MOE] (2001). Health and Safety Standards in Educational Institutions Circular Retrieved from http://cwsglobal.org/wp-content/uploads/2017/01/CWS-SSZSchools-Manual_Kenya.pdf

14. Ministry of Education [MOE] (2008).The development of Education: National Report of Kenya.Report Presented at the International Conference on Education. Geneva, 25-28.

15. Niza, S. (1995). Para umaconstruçãofunctional da LinguagemEscrita (Unpublished paper)

16. Owiti, F. O. \& Associates (2004). Qualitative Evaluation of Kenya Early Childhood Development: Final Report Ministry of Education, Science and Technology 
17. Psacharopoulos, G. \& Woodhall, M. (1985). Education for Development: An Analysis of Investment Choices. Washington: Oxford University Press.

18. Philippine Education for All (2015). Implementation and challenges (Phlippines-EFA-MDA-1 PDF accessed on 23/2/2016.

19. Psacharopoulos, G. \& Woodhall, M. (1985). Education for Development: An Analysis of Investment Choices, Washington: Oxford University Press.

20. Republic of Kenya (2006).Early Childhood Development Service Standard Guidelines. Government Printer, Nairobi.

21. Republic of Kenya (2014). Education for all: The 2015 National Review. Nairobi: Government Printer.

22. Republic of Mauritius (2009). Education and Human Resources Strategy Plan 2008- 2020: Ministry of Education, Culture and Human Resources.

23. Sarantakos, S. (2013). Social Research(4 ED), Palgrave Macmillan, USA.

24. The Basic Education Act. No. 14 of 2013 (2013).Education, vocational guidance and training Retrieved from Kenya Law, http://www.kenyalaw.org PDF of Act on May 25, 2019

25. UNESCO (2008). Global Monitoring Report: Chapter 2. The Six Goals: How Far have we come? UNESCO, Paris.

26. Waller, S. (2015). "Early learning brings all the difference from the children from the ethnic minority communities." www.unicef.org/ Cambodia accessed on 18/9/2015.

27. World Bank (2006). World Development Report (32204): Equity and Development, the World Bank, Washington, D.C.

28. WHO (1997). Primary School physical environment and Health Information Series on SchoolHealth: Document 2. Geneva: WHO.

29. Young, M.E. (1996). Early Childhood Development: Investing in the Future. Washington: The World Bank. 